\title{
Tecendo a Rede de Cuidado: Referência e Contrarreferência
}

\author{
Burattini, Paula Marques de Freitas; Adolpho, Carolina Vieira Tomanik; Fajardo, Aline;
} Silva, Joana Teixeira Ferraz da; Sousa, Ana Paula Geraldo de; Araújo, Fabiane A. Lourenço de

Universidade Federal de São Paulo _ pa_marques@yahoo.com.br

Introdução: o programa de Residência Multiprofissional, norteador deste relato, visa ao trabalho em equipe na perspectiva da integralidade do cuidado e a integração da academia com o serviço. para viabilizar sua execução foi firmada parceria entre a Universidade, Hospital de Ensino e Secretaria de Saúde do município. Durante o cotidiano institucional os residentes encontraram dificuldades de efetivar espaços de discussão intersetorial e entre si, sendo necessário o desenvolvimento de novas estratégias para a corresponsabilização do cuidado com usuário. em vista dessas dificuldades, resgatamos a definição de referência e contrarreferência: modelo de organização que assegure a atenção integral aos usuários por meio de critérios, fluxos, mecanismos de pactuação e vínculos entre as equipes e a rede intersetorial em seus diferentes níveis de complexidade, viabilizando encaminhamentos resolutivos. para facilitar a comunicação entre os serviços foi confeccionado, pelos residentes, um instrumento que contempla dados relevantes, como identificação, histórico de vida, processo saúde-doença e intervenções no cuidado do usuário. Objetivo: Relatar a experiência da utilização desse instrumento a fim de operacionalizar e potencializar o fluxo do trabalho em rede, segundo as perspectivas do SUS. Método: Trata-se de um relato de experiência que explora aspectos do processo de elaboração e implicações do uso do instrumento no cotidiano de trabalho dos cenários de práticas do programa. Resultados: Percebeuse que o hospital, embora inserido na rede de serviços, encontra dificuldades na articulação com essa devido a sua estruturação do cuidado. Assim, tentativas de contatar equipamentos para encaminhar os usuários no pós-alta foram iniciadas. Dada a busca pelos encaminhamentos corresponsáveis e a dificuldade de comunicação entre os profissionais, foi confeccionado o instrumento de contrarreferência para facilitar a continuidade no cuidado favorecendo o caminhar do usuário pela rede de serviços. Antes de se enviar este instrumento para o equipamento, é realizado contato telefônico para envolver outros profissionais na atenção ao sujeito que teve modificações em seu processo saúde-doença. Neste contato nos deparamos com estranhamentos dos profissionais, com posterior entendimento da importância e gratificação, firmando parceria e corresponsabilização do cuidado. o instrumento permitiu a aproximação dos diferentes serviços, auxiliando na resolutividade e fluidez na atenção integral ao usuário; e possibilitou novos olhares dos profissionais acerca do reconhecimento e valorização do cotidiano extra institucional do indivíduo. Os novos olhares se fazem presentes no momento em que discutimos a quebra dos préconceitos que rodeiam o usuário. É no tecer e costurar a rede de equipamentos que os residentes puderam vivenciar e conhecer melhor seus serviços, bem como, novos espaços de discussão para garantir a continuidade do cuidado e atenção ao usuário.

Burattini, Paula Marques de Freitas; Adolpho, Carolina Vieira Tomanik; Fajardo, Aline; Silva, Joana Teixeira Ferraz da; Sousa, Ana Paula Geraldo de; Araújo, Fabiane A. Lourenço de. Tecendo a Rede de Cuidado: Referência e

Contrarreferência. In: Anais do Congresso Internacional de Humanidades \& Humanização em Saúde [= Blucher Medical Proceedings, num.2, vol.1]. São Paulo: Editora Blucher, 2014. ISSN 2357-7282

DOI 10.5151/medpro-cihhs-10608 